\title{
RHEUMATISM IN SWEDEN *
}

BY

\author{
W. S. C. COPEMAN
}

\section{Historical}

A survey of rheumatic diseases was made by the Swedish Government at the beginning of this century, and the situation was found, as had been expected, to be that this group of diseases was involving the country in great expense, and that treatment facilities were non-existent for a large proportion of cases. In Sweden the large majority of workers are insured, and become eligible for pension based upon their previous income if they become incapacitated; rheumatic cripples thus become pensionable.

In 1915 the National Pensions Board completed an arrangement whereby a variable number of beds was reserved for these cases in general hospitals if they were unable to continue with their employment. Their fees were paid by the Board for a period up to two months.

In 1918 Kahlmeter, who was C.M.O. for the Pensions Board, conducted a further survey and found that in that year there were more than 50,000 patients pensionable from this group of diseases, whilst 5,000 new cases came into this category during the year. As a result of this the Board in 1920 bought two spas, Nynäshamn and Tranas, and built special rheumatic hospitals in these, each capable of accommodating 200 patients. A third was added in 1923 (Are). Cases were allocated to these from the central office in Stockholm.

In 1926-1927 the policy changed, and it was considered desirable that these patients should be accommodated and treated in special centres situated in the five chief regional general hospitals of the country. The advantages were considered to be: (a) full facilities for ancillary services and special opinions; (b) increased interest in academic medical circles; (c) facilities to train physicians for diagnosis, treatment, and research in this field.

By the end of 1927, 345 beds had been established in this way. The largest unit was at Lund (120 beds). In each case they came under the general direction of the Professor of Medicine; a physician of the rank of Docent (Reader, lecturer), with a special interest in the subject, being appointed in charge; a consulting orthopaedic surgeon, being specially attached and having beds in the same block.

This Brief Report on the Incidence and Treatment of the Rheumatic Diseases in Sweden is based on a visit made in July to Malmo, Stockholm and Lund, by kind permission of the Royal Swedish Government, and Board of Health.
Two years later another such department was added in the Norrköping region.

This system worked well from the administration point of view, but conflict developed between the professors of medicine, where these were not particularly interested in the subject, and the Docent in charge, the former taking the view that rheumatism is only a minor field of general medicine and that specialized consideration would give exaggerated importance (Svartz); the Docents' view being that, with the specialized facilities and interest at their disposal, great advances could be made if the repressive academic influence could be removed, and the subject become a free speciality with the status of a special department (Edström). Some wished to revert to the special hospital system, with the addition of visiting specialists (Sunderlin) from regional centres.

\section{Royal Commission 1937}

In 1937 a Royal Commission was appointed under the Chairmanship of Professor Höja, the President of the Board of Health, and the whole problem was discussed anew.

It was decided to provide an additional 1,200 beds, in units of 60-120, and place these units in the eight chief central county hospitals. In this way each unit would be in the centre of a region containing 150-200,000 population. The existing general hospital units were retained under the professors of medicine, but these new beds were to rank as independent departments, although the medical staff might be drawn from the professorial departments in the general hospitals. The programme provided for their completion in 5-8 years, but the occurrence of the world war, coupled with some further opposition from the professors of medicine, led to postponements. The Commission endeavoured to compromise with the professors by offering them the use of all beds not being used for rheumatic purposes for general medical overflow, but no real progress was made.

\section{Recent Activity and Proposals}

As the result of this stasis a new and larger commission was appointed in 1941, which included representatives of the professors and the Docents.

In the summer of 1943 a member of this commission, Docent Edström, made an up-to-date survey of the present position and needs. He made a 
preliminary but exhaustive census of rheumatic diseases in four large districts - two coastal and two inland. The total population of these was 48,000 , of whom he found that $2.4 \%$ had, or had had, rheumatic fever, $2 \%$ rheumatoid arthritis, $1 \%$ osteoarthritis, and $2.6 \%$ sciatica. Other forms of nonarticular rheumatic disease are not mentioned. He found, therefore, that $1 / 25$ th of the population were suffering with one of these forms of rheumatic disease at the time of his enquiry. From this it was calculated that in Sweden, with a population of $6 \frac{1}{2}$ millions, 100,000 individuals were permanently incapable of work, in spite of the fact that the arrangements for treating this group of diseases are probably the best in Europe.

Under the authority of the Commission, 4,000 doctors were circularized, of whom 2,000 replied, two-thirds very fully. In this. way 66,500 case reports were obtained of which 5,000 were found to be duplicated $( \pm 61,000)$. Of these, 21,000 patients had been hospitalized for varying periods, whilst 5,000 had been too bad for this. A study was made of the length of stay of those patients who had done well, and an average minimum period of hospitalization was recommended as the result. This is as follows:

Group I.-Acute rheumatic polyarthritis .. 60 days Group II.-Chr. polyarthritis (mostly rheumatoid arthritis ..

Group III.-Arthrosis .

Group IV.-Other types, including fibrositis and sciatica 90 days 40 days

To provide this accommodation for the present need would require about 3,000 additional beds, of which half would be to serve those patients at present unable to obtain any treatment; the rest, to provide for the full period of hospital stay necessary on the above calculation in order that patients do not have to be discharged prematurely from the hospitals to make room for others, as at present.

It was realized that, since research had by then started in the special units of the general hospitals, new light might be thrown on therapy in the near future which would render the provision of beds on this scale unnecessary. In view of this, it was decided to authorize the immediate provision of 2,000 of the 3,000 beds required for present purposes. It was considered that this would be sufficient to deal with Groups I and II, which constitute numerically the greater problem in Sweden.

In 1944, the Commission were satisfied that this solution of the problem was therapeutically administratively on the right lines, but the problem of after-care and rehabilitation had become urgent if these patients were to be restored to high wage-earning capacity, and this field was exhaustively explored. Their report on this has just been published.

Perhaps their most interesting recommendation, which has been approved by the Government, is the institution of " after-care beds" in every hospital treating rheumatic and orthopaedic cases, on a basis of $20 \%$ of the total beds employed in these ways. This means the provision of 20 of such beds for every 100-bedded unit. These beds are to be provided immediately, and are of a very much cheaper type than those of the main hospital, the plan (in report) suggesting that they are more in the nature of glorified huts.

When the rheumatic patient has reached the end of his time in the main hospital, and provided he is capable of looking after himself to a large extent, he will be transferred to one of these beds but will continue under the regular observation and treatment of his hospital physician. Besides saving space and increasing turnover in the main hospital, this plan is considered to condition the patients to the changed environment to which they will have to return in their homes on completion of treatment - the sudden transition from complete hospitalization to home being thus avoided.

Previously patients who did not seem susceptible to much improvement, but who needed further treatment, on discharge from a general hospital unit were transferred to hospitals for chronic disease which are situated in each country district. These cases, being beyond the range of influence of the general hospitals, tended to become neglected. Recently these have been moved and regrouped at the Regional Medical Centres. Since this was done the improvement or cure rate has gone up by $20 \%$ mostly in the field of rheumatic diseases - with a corresponding saving of public funds. The Commission therefore recommend that these beds be also extended by 400 for the rehabilitation of longterm rheumatic cases.

The proposed total increase in the beds to be allocated for the rheumatic diseases in Sweden is therefore 400 in Class A (general hospitals), and 600 in the 8 Regional Centres, where the physician in charge will be independent of the Professor of Medicine. Such independent units will then average 120 beds each with a whole-time or nearly wholetime specialist physician in charge. In view of the size of these units under these proposals, the Professors of Medicine have realized that they would not have been able to accept responsibility for them in addition to their present commitments, and have partially withdrawn their previous objections.

The above is the outline of the Central Government's scheme, but as the provincial governments are largely autonomous in health matters it is left to them to start on whatever part of the scheme which seems to them most immediately advantageous. The Central Government will pay for the whole cost of building and half the cost of the first years' running expenses. After that, finance has to be agreed between the Provincial and the Central Government. Patients who are able to do so are expected to pay three Kronor per diem under this scheme, of which the full cost is estimated at 12 Kronor.

It is realized by the Board of Health that this extension of their programme for dealing with rheumatic diseases will involve an increase in the number of physicians specializing in this group of diseases. 
Their preliminary view is that this should involve 2 years (minimum) postgraduate work in general medicine, one year as assistant in an orthopaedic department, and a further year in a physiotherapy department, spa hospital, or special department for rheumatism. In addition they consider that 6 months' study of the subject abroad should be insisted upon wherever possible.

As an indication of the degree of interest in this field of disease in Sweden it may be mentioned that the public were invited to contribute to a special fund on the occasion of King Gustav's 70th and 80th birthdays, and that the whole proceeds of the former were allocated for cancer, whilst the proceeds of the latter have been allocated for extension of treatment facilities, hospital beds, and a research institution (at the Karolinska Hospital) for the rheumatic diseases. This fund amounted to $6,500,000$ Kronor. A rheumatism society under government patronage with branches in all parts of the country is being founded to maintain this interest.

(It is proposed to allocate the next fund, if the King reaches his 90th birthday, to the psychoneurotic diseases.) 